\title{
Adaptive Voltage Regulation Control Strategy in a Stand-Alone Islanded DC Microgrid based on distributed Wind / Photovoltaic / Diesel/ Energy Storage Hybrid Energy Conversion System
}

\author{
Adel Elgammal and Tagore Ramlal
}

\begin{abstract}
An adaptive approach for optimal tuning of a SMC for an automated voltage regulator system is displayed in this study. The approach is centered on hybrid of the GA and MOPSA. In addition, unique objective functions for the controller's parameter optimization are suggested. The performance of the resulting perfect sliding mode controller is confirmed by comparing it to controllers adjusted using various techniques that have been published in the literature. The simulation outcomes indicate that controllers tuned with the projected MOPSO and GA algorithms outperform controllers tuned with existing methods. In addition, a comparison study is performed to select the best controller for use in AVR systems. The suggested algorithm's major benefit is a considerable boost in convergence speed. With step changes and step load modifications in input wind power, the system model with builtin intelligent controller is generated in MATLAB/SIMULINK. The benefits of the recommended intelligent control algorithm are confirmed by comparing the outcomes of the sliding mode controller and the projected MOPSO self-tuned controller. The findings show that the hybrid Wind/PV system's reactive power adjustment capabilities. When used in conjunction with BES, it is extremely successful in optimising the voltage profile although providing active energy to local load.
\end{abstract}

Key words - Automatic voltage regulation, Battery energy storage, DC link voltage, Distribution system, intelligent smoothing control, Reactive power, Sliding Mode controller, Solar photovoltaic (PV), Wind Energy, wind/PV hybrid power system.

\section{INTRODUCTION}

In remote places where expanding the public grid is difficult, there is an increasing need to create and execute economic power solutions to meet power burdens while simultaneously minimizing potential environmental repercussions [1]. Hybrid power systems cantered on biomass, photovoltaic, and wind, for example, are very interesting solutions with a lot of promise for satisfying the local demands of remote areas in a sustainable and effective way [2]. The abundance of sun and wind energy found in distant regions allows for the utilization of RE resources for electricity generation [3]. Because renewable energy sources are unpredictable and fluctuate in nature, achieving a stable and high-quality supply necessitates a proper control mechanism to keep frequency and voltage within prescribed parameters [4]. The off grid hybrid power structure investigated in the present study is made up of photovoltaic $(\mathrm{PV})$, wind, and diesel generators (DG). This sort of off grid hybrid power structure has previously been installed on a few

Submitted on July 04, 2021

Published on July 26, 2021.

Adel Elgammal, The University of Trinidad and Tobago UTT, Utilities

Engineering, Point Lisas Campus, Trinidad and Tobago. isolated settlements or tiny islands [5]. The reactive power demand of the load, along with reactive power utilized through induction generator linked to the wind turbine affect system's reactive energy requirements. Inadequate voltage control is caused by a reactive power imbalance in structure. As a result, system voltage variations may surpass the voltage allowed limits, causing end users to be unsatisfied with the quality of the power supply [6]. Previous research has been published that used a static synchronous compensator and a static voltage compensator for reactive power to manage the voltage of off grid hybrid power structure [7]-[9]. The possibility of distributed energy resources with a suitable electronic power link to provide reactive power to the grid along with active power supply has been considered in [10]. In off grid hybrid energy systems, the capacity of PV inverters to create or utilize reactive power to regulate voltage might be an answer to the power supply issue.

Inverter control is usually done using traditional PI and PID controllers. Under rated working circumstances, the proportional-integral controller with fixed gains constants executes admirably. However, it fails to provide greater responsiveness under varying operating circumstances [11]. As a result, to manage the effects of changing structure variables, control structures necessitate a flexible controller with an adaptive character. The ability of Fuzzy Logic Control (FLC) to function in a wide range of operating situations has shown its strength. FLC rules are expressed in natural language words and are flexible fuzzy rules that mimic the approaches of a human operator [12], [13]. The controller's proper tuning is critical for the automated voltage regulator system's intended voltage response. To that purpose, a vast number of existing research focus on identifying the best parameter values. The particle swarm optimization [19]-[21] and genetic algorithm [14]-[18] are two of the most prominent optimization approaches based on the use of metaheuristic algorithms. Also, Other algorithms can be used for optimization, such as multi-objective extremal optimization (MOEO) [38], chaotic ant swarm (CAS) [36], [37], craziness PSO (CRPSO) and velocity update relaxation PSO (VURPSO) [35], harmony search algorithm (HSA) [34], artificial bee colony (ABC) [32], [33], symbiotic organisms search (SOS) [31], chaos optimization algorithm (COA) [30], many optimizing liaisons (MOL) [29], teaching-learning-based optimization (TLBO) [28], ant colony optimization (ACO) [26], [27], cuckoo search (CS) [24], [25], whale optimization algorithm (WOA) [23], improved kidney-inspired algorithm (IKA) [22], and others.

(e-mail: adel.elgammal ${ }^{@}$ utt.edu.tt)

Tagore Ramlal, The University of Trinidad and Tobago UTT, Utilities Engineering, Point Lisas Campus, Trinidad and Tobago. 
The fact that there are so many optimization approaches implies that the current findings can be improved much further.

PV and wind power production technologies have the drawback of having an unpredictable power output, which can severely influence microgrid and utility operations. This problem can be overcome by combining solar and wind energy with a battery energy storage device. Control techniques for such hybrid generating systems must be devised in order to efficiently dispatch electricity. As a result, a fuzzy-logic-based wavelet filtering control approach for smoothing the output fluctuation of wind and photovoltaic hybrid power production structure is presented in this work. Because voltage management is so important for supply quality, regulating reactive energy has become an significant part of off grid power structure. The gradual penetration of solar photovoltaic (PV) and wind turbines in the distribution system is causing voltage problems. During peak PV and wind generation and peak load demand, the problem becomes more complex. The voltage profile is managed in this study using off grid hybrid power structure with VAR assistance. The wind power provided by DE along Synchronous Generator, a solar system with an inverter, and an induction generator make up the DC-microgrid under discussion. The combined functioning of the BES and hybrid PV/Wind is being researched to ensure that the distribution system's voltage profile is enhanced. Variations in PV and Wind generation and load are taken into account to ensure that the planned scheme is effective. The current standard for smoothing intermittent solar or wind power production is the battery energy storage system. When an inverter is large, its reactive current capacity rises while inputting maximum electric power, allowing it to supply the system with the reactive power support it needs to keep the voltage profile flat. This paper proposes an actual grid-connected use of battery energy storage and PV/Wind to manage direct current associated voltage and rectify reactive power while delivering active power to local consumers. For minimizing output power fluctuations of BESS/PV/wind hybrid power generating systems, sliding mode controller based a voltage smoothing control approach based on MOPSO is presented. This study presents an intelligent control based on a SMC technique with MOPSO for controlling reactive power of a battery, wind, or PV inverter to manage load bus voltage. In grid-connected mode, effective charging and discharging of the battery has also been confirmed under changing power supply and varied load conditions. The findings show that the proposed hybrid system structure, as well as associated control, has potential applicability in current renewable energy-based grid developments. This article looks at voltage regulation for a DC-microgrid system with constant power demands, constant resistance, and battery, wind, and PV array energy storage. To modify the controller's settings, this study presented a self-tuned sliding mode controller based on MOPSO. The voltage profile stability is investigated using the suggested controller under various load conditions and changing operational conditions. The suggested regulators may achieve MPPT, load voltages of the photovoltaic power output, and DC-microgrid control objectives, such as bus global regulation. The control approach's important part is to keep the grid linked hybrid system consistent under a variety of operating situations. The capacity of the hybrid model to change reactive power has been used to enhance power quality and system dependability.

\section{CONFIGURATION OF HYBrid POWER SYSTEM}

The suggested Battery/Diesel/Wind/PV Hybrid power structure considered in this research is depicted in Fig. 1. A storage battery structure, variable wind speed turbine with Solar photovoltaic and DFIG structure with DC-AC inverter, and DG (Diesel Generator) with two RESs and excitation control make up the Hybrid power system setup. The whole load is grouped together and linked to a single bus. A common coupling bus connects these two RESs to the system. Two transmission lines and two transformers link this common connection bus to the grid. This centralized DC bus HPS topology has several advantages, including ease of control, cost, and control reliability. At nominal operational solar irradiance and cell temperature, the PV modules evaluated provide a peak output power of $90 \mathrm{~kW}$. A total of twenty four solar panels are linked in series, while another 20 are linked in parallel. The solar PV system is made up of a total of 480 panels. For the wind turbine, a $180 \mathrm{~kW}$ PMSG type generator is being explored. The system's maximum connected load is $70 \mathrm{~kW}$, which includes a forty kilowatt base load and two other $15 \mathrm{~kW}$ loads. Because it is considered an island electrical load, the load is changeable. The BESS (Battery Energy Storage System) has a capacity of 400 kilowatt-hours. One string comprises of seventy two $120 \mathrm{Ah}$ batteries linked in series and capable of storing 100 kilowatthours of energy. Three of these strings are linked in parallel to deliver three hundred kilowatt-hours of energy, implying that the Battery Energy Storage System can power an $80 \mathrm{~kW}$ load for 3 hours and 45 minutes. MATLAB/ Simulink is used to model the system controllers and components. Changing the amplitude of the injected current into the $\mathrm{AC}$ side is commonly used to adjust the direct current bus voltage. The direct current bus voltage lowers when the injected AC current is raised, and vice versa. However, on the AC side, this method may result in a considerable drop in power quality. Two stages of DC-DC converters are utilised in the proposed HPS technique to enable DC voltage stability and MPP operation, as illustrated in Fig. 1. The boost converter is the first stage in the MPP operating process. The direct current bus voltage is controlled through the second converter, the Buck-Boost converter. A SMC based MOPSO for the HPS is proposed in this study, and it can electrify a village load or a $55 \mathrm{~kW}$ Peak industrial load. The output voltage of a solar PV system varies from $200 \mathrm{~V}$ to $450 \mathrm{~V}$ depending on temperature and sun irradiation intensity. Depending on the wind speed, the wind generator's output voltage ranges from 200 to 500 volts. To increase the voltages, the duty cycle of the Enhance converter is adjusted in each case. The duty cycles are taken from the respective Sliding Mode Controllers. Both the Wind and Solar Generators use DC-DC Buck-Boost converters with Sliding Mode controllers to keep the DC Bus voltage at $450 \mathrm{~V}$, as shown in Figure 1. STATCOM is linked to the structure at the Power Control Centre and may be adjusted to enhance system performance based on the voltage at the Power Control Centre. STATCOM is made up of Voltage Source 
Converters, a coupling transformer and a direct current capacitive energy storing device that connects the Voltage Source Converters to the Power Control Centre's power network in a shunt configuration. Based on the frequency of the AC power supply, the Voltage Source Converters create a set of controlled voltages. Depending on the difference between the reference voltage and the Power Control Centre voltage, STATCOM can work in capacitive or inductive modes, with $1 \mathrm{pu}$ assuming a $450 \mathrm{~V}$ base voltage. If the voltage amplitude at the Power Control Centre decreases, a leading current is injected from STATCOM to the grid at the Power Control Centre, resulting in reactive power generation by the STATCOM (capacitive mode). A trailing current is injected from STATCOM to the grid at Power Control Centre when in inductive mode. As the Power Control Centre grows, the STATCOM absorbs the reactive power. There is no power exchange if the Power Control Centre voltage is not altered. During fault occurrences, this controlled injected current from STATCOM reduces voltage swings in the Power Control Centre. The main contribution of the research is the near-optimal scheduling of two sliding mode controllers to efficiently drive the STATCOM and, as a consequence, enhance the hybrid system dynamic performance by minimizing voltage fluctuations. On the input side of the inverter, the PV system studied in this study is assumed to have a rigid direct current supply. As a result, as presented in Fig 2, the control technique is constructed on a self-tuning sliding mode controller that is limited to inverter control alone. The PV grid connected inverter's control is supplemented with voltage control depend on diesel generator power output. The local voltage control circuitry creates the inverter's reactive power reference Qref depending on current characteristics and the local voltage control target. By substituting this reactive power reference Qref, the diesel generator is coupled to a function for regulating local voltage. Distributed photovoltaic production, according to the MPPT, achieves the reference value of the inverter's diesel generator voltage in real time. In order to maximize PV power production, it assembles current and voltage output from photovoltaic cell array. The present iqref reference value's active component is generated from outer loop controller of direct current voltage. The current iqref reactive component of reference value is generated from outer-loop control of reactive power. The local voltage control technique provides reference value for the reactive power Qref. Finally, the Pulse Width Modulation drive signal of an Insulated Gate Bipolar Transistor is generated by combining PWM generating technique with current management. The control scheme's main purpose is to adjust voltage and reactive power of control inverter for an active power based on the local grid's reference demand. Two controlled outputs phase angle QIN and PIN, as well as amount of inverter voltage, are adjustable inputs. As a result, the control structure is divided into two loops, first for active power control and second for voltage regulation. When the operating point of the system changes owing to disturbances, the control assembly based on fixed gain SMC exhibits inadequate responsiveness. For optimal performance, the gains of the voltage control loop's sliding mode controller are dependent on the size of reactive power load. Fig. 3 displays block schematic of the entire control architecture for Battery

\section{Energy system.}

The considered Machine Side Converter (MSC) in the system is the three-phase AC/DC converter of the conventional topology of two-level voltage inverter. The use of Rotor Field Oriented Controller to the control of DFIG with MSC is based on vector control. Fig. 4 depicts the full control system for GSC and MSC using Space Vector Modulation. In the proposed control scheme, there are three controller loops. The outer controller loop's goal is to regulate generator's rotating speed. Two inner control loops are designed for control of individual components of the stator current vector. The sliding mode controller in the outer control loop provides by control, that the generator speed is following the reference course of optimal speed wopt of the wind turbine, at which point full power of wind turbine is produced. The reference signal isq* of the q-component of stator current vector is generated as the output control signal of the speed control loop. The reference signal isq* determines the desired electromagnetic torque of DFIG. Both stator current vector components: isd and isq are regulated thorough two inner control loops with sliding mode controllers. In the control system, the method of zero d-axis stator current control is realized, and for this reason, the reference component isd* of stator current vector is set to zero value. As a result of this, the stator current vector will be equal only to its q-axis component isq. With isd $=0$, the generator`s electromagnetic torque is proportional to current component isq on q-axis. The stator current reference isq* is achieved in the control system by using the operation of the MPPT block. The reference dq-axis components isd* and isq* of stator current vector are compared with the real current components isd and isq, obtained from measurement and transformation of real stator phase currents. As the result of the comparison operation, the error control signals are generated and sent to the individual sliding mode controllers. Decoupling blocks have also been incorporated in the control system to provide excellent control performance. Each decoupling block's output signal is added to the appropriate controller's output signal. In this way, the resultant control signals that form the dq-axis reference components $\mathrm{vpd}^{*}$ and $\mathrm{vpq}^{*}$ of the stator voltage vector are obtained. These reference voltages are subsequently converted from a spinning d-q-system to a fixed one and supplied to the MSC's Space Vector Modulation block. The Grid Side Converter is the three-phase DC/AC converter of the conventional topology of two-level voltage inverter. For the control of GSC the modern control method based on Direct Power Control with SVM modulation has been implemented. The GSC's primary goal is to execute the system's fundamental control functions. Controlling the GSC's DC link voltage along with instantaneous reactive and active power provided to alternative current grid is among these responsibilities. In the GSC's control system; there are three control loops with sliding mode controllers. The GSC and DC bus DC connection voltage is regulated by the outside control loop. The reactive and active power delivered to loads and to AC grid is regulated by 2 inner control loops. The reactive and active power values are measured and then estimated in specific blocks before being associated to reference values. The reference of reactive grid power is set to zero in the common operation of the control structure in order to run the 
structure at unity power factor. The active grid power reference is calculated by multiplying the converter's measured DC voltage by the grid current vector component's reference value. The external control loop provides the reference value for grid current vector constituent. The reference grid voltage vector components and for GSC control are determined by the output signals from the inner PI controllers. The control signals are obtained by transforming these reference voltages from a spinning d-q-system to a stationary system, and they are transmitted to the GSC's SVM block.

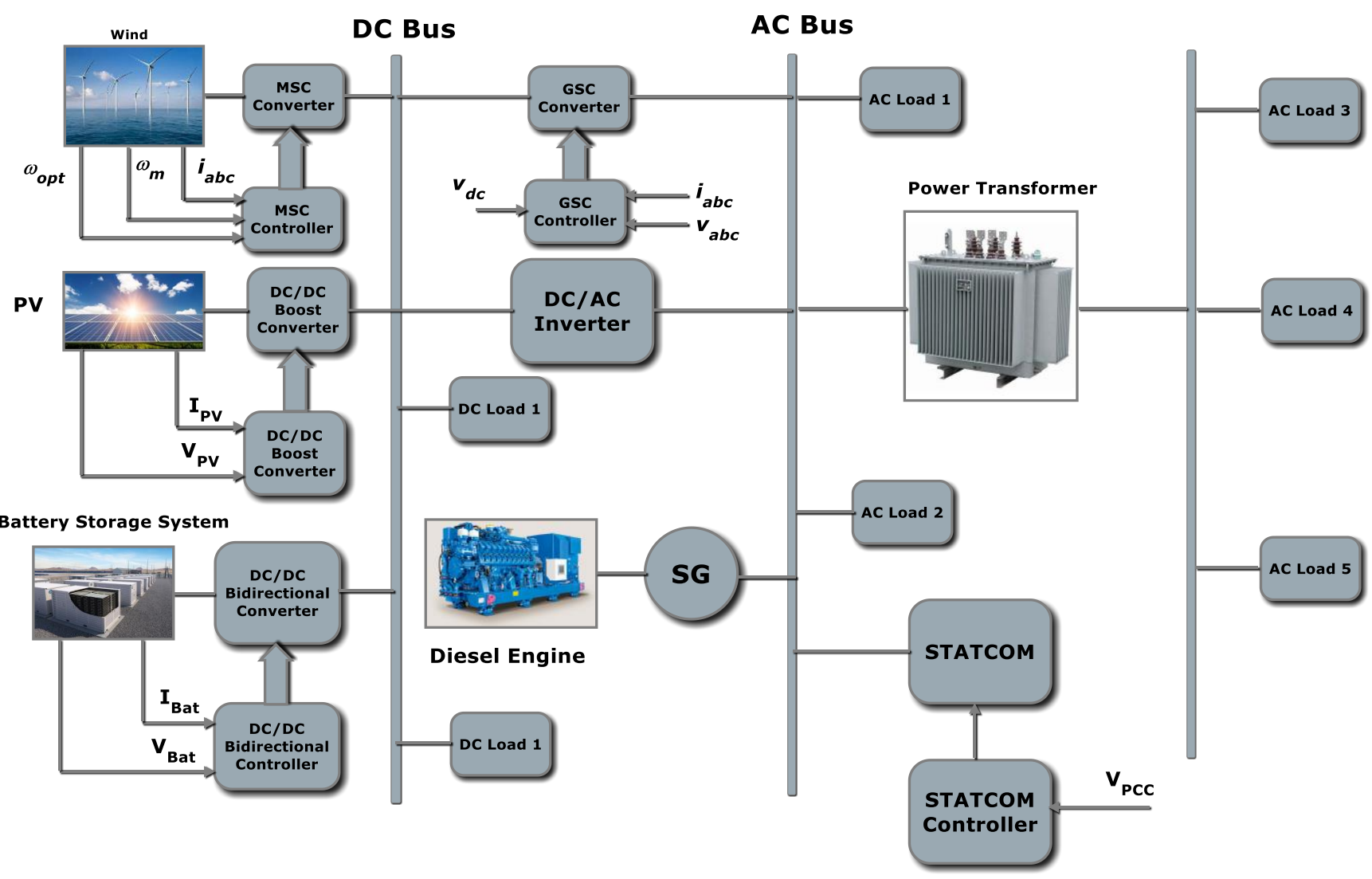

Fig.1. An off-grid hybrid power structure is depicted in block diagram.

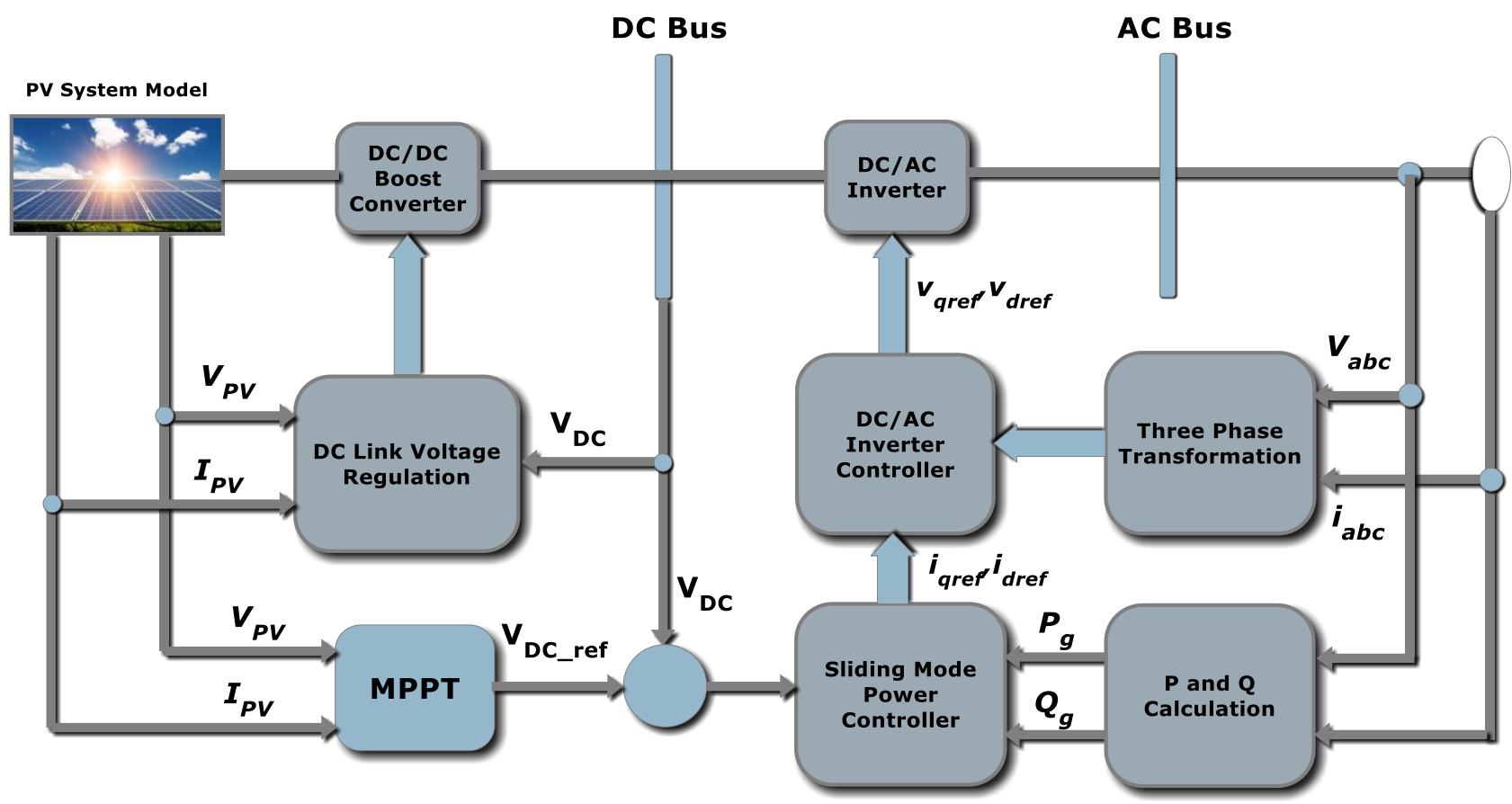

Fig. 2. The complete control strategy for the PV unit is depicted in this block diagram. 
DC Bus

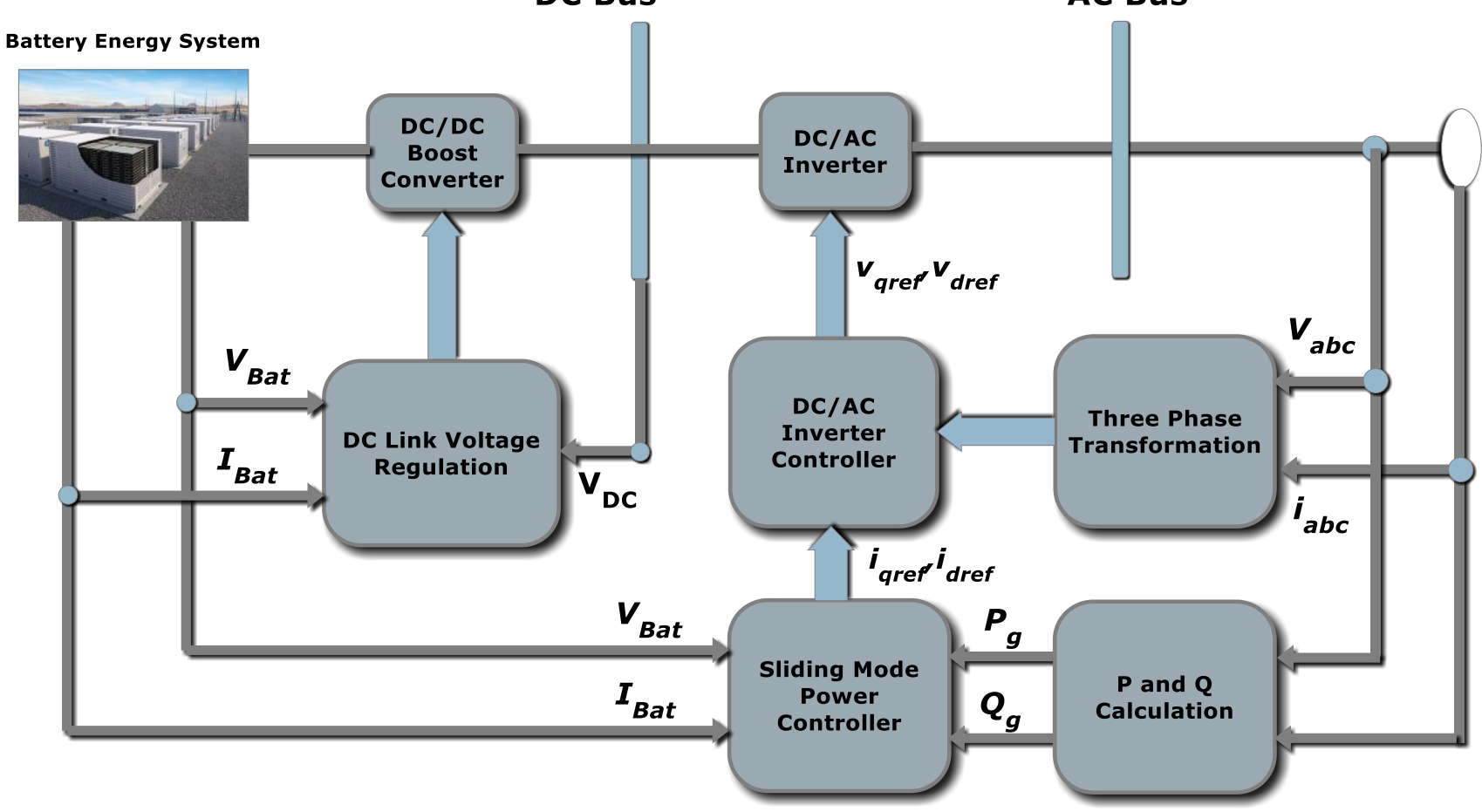

Fig. 3. The complete control strategy for the ES unit is depicted in block illustration.

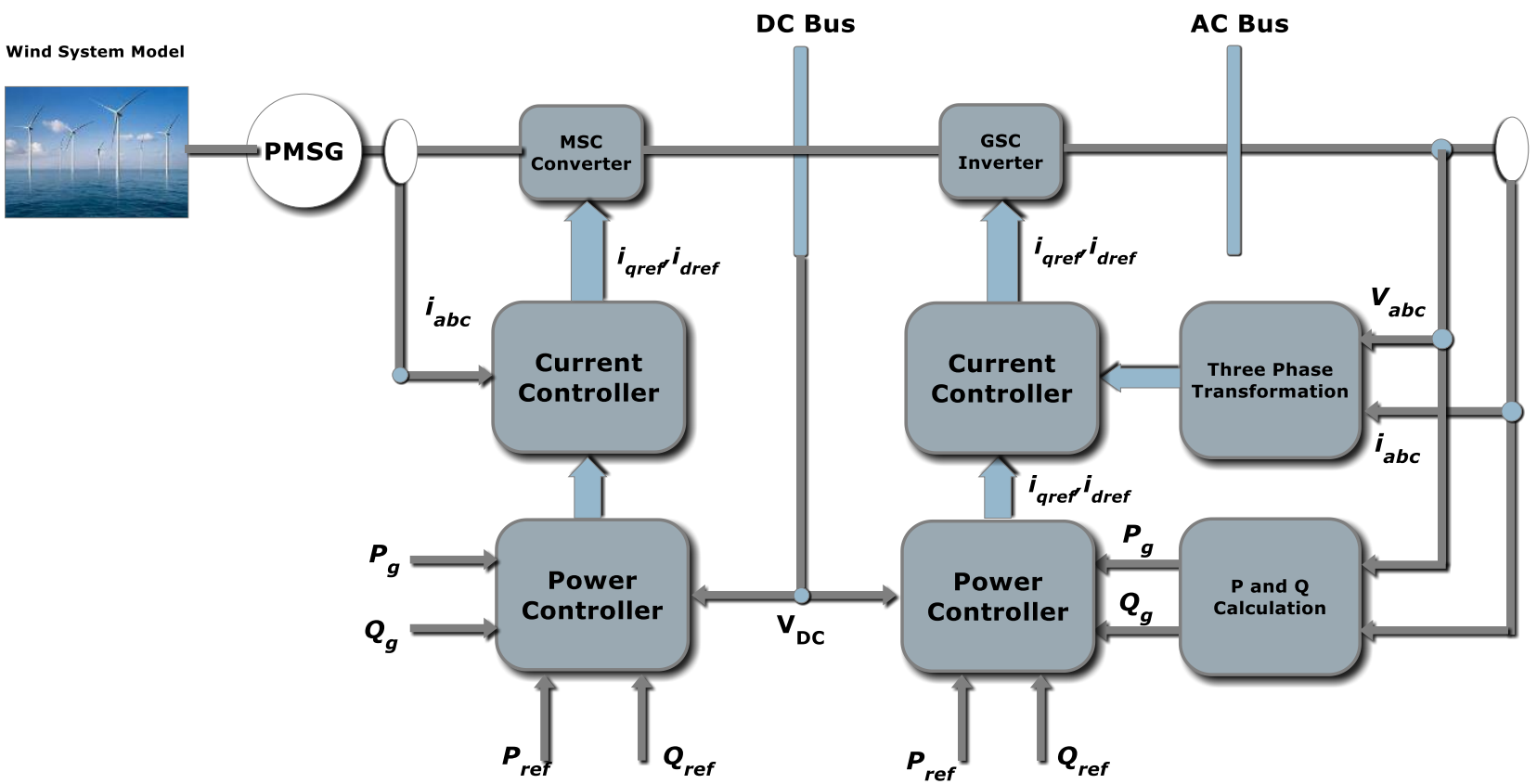

Fig. 4. The complete control strategy for a wind turbine is depicted in this block diagram.

The Sliding mode controller is an accurate, non-linear, and resilient control method for error signals e(t) or forwarding control system states onto the sliding surface. Once the sliding surface is reached, the control error signals are kept near to the sliding surface. The sliding surface has the following properties:

$$
S(t)=\left(\frac{d e(t)}{d t}+\lambda_{1} e(t)+\lambda_{2} \int e(t) d t+\lambda_{0}\right) \times k
$$

where $\mathrm{e}(\mathrm{t})$ is error signal and $\mathrm{k}, \lambda 0, \lambda 1, \lambda 2$ are positive constants. A nonlinear mapping between change of error signal and error signal is used to create the SMC parameter settings $(\mathrm{k}, \lambda 0, \lambda 1, \lambda 2)$. The following equation is used to calculate the change in the error signal $\Delta \mathrm{e}$ :

$$
\Delta e(t)=e(t)-e(t-1)
$$

To allow the controller to 'see' the outside control system, the change of the error signal and the error are multiplied by the scaling factors $\beta 1$ and $\beta 2$. The MOPSO tuning technique may be used to produce resilient and rapid monitoring of control system error signals by changing the SMC parameter values $(\mathrm{k}, \lambda 0, \lambda 1, \lambda 2)$. The parameters tuning idea is centred on the fact that sliding surface slope $\lambda 1$ ' large value results in longer settling and overshoot times and shorter rise times. 
Whereas sliding surface slope $\lambda 1$ 'small values result in faster reaching and slower tracking, large values result in faster reaching and slower tracking. In the face of external disturbances, the intercept $\lambda 0$ is adjusted to minimise the reaching time and tracking error. Large $\mathrm{k}$ values result in a reduced reaching time but a large chattering impact. The error signal and its modification have a significant impact on the control system's dynamic performance. As a result, these two inputs are passed to the MOPSO, and the SMC is used to adjust the objective functions by finding optimal values of four gains $(\mathrm{k}, \lambda 0, \lambda 1, \lambda 2)$. MOPSO is in charge of scheduling the parameters of two SMCs. The MOPSO algorithm is used to reduce the integral of the square of error. The discrepancy among the PCC and reference voltages is an example of such an inaccuracy. The inverter's sliding mode gain must be modified for optimal tuning due to the changing nature of the load. The suggested control system is centred on the MOPSO algorithm to auto regulate gains SMC which provides the convenience of sliding mode with voltage control flexibility. The gains of the SMC are continually adjusted by the MOPSO according to operational conditions in MOPSO control. The specification of system parameters is the first step in the proposed MOPSO sliding mode controller. The voltage variation at the load bus is the major controlled variable, while controllable variables include inverter reactive power. Wind speed perturbation and reactive power load demand are the disturbances studied. The SPWM method is used to produce switching pulses for STATCOM 3 level inverter in this study. As a result, the inverter voltage delivered to grid is controlled by the phase angle control. The MOPSO method for obtaining near-optimal sliding mode controller settings for STATCOM is the paper's main contribution. The MOGA optimization approach is utilised to provide an unbiased comparative examination of dynamic performance of system while controlled with optimised two sliding mode controllers. MOPSO is primarily used to determine near-optimal sliding mode control parameters for controlling reactive power flow between the STATCOM and grid based on hybrid system. As may be seen in Fig. 6-b, the STATCOM is driven by two distinct sliding mode controllers. Each controller in the sliding mode has its own set of gains. The MOPSO optimization method is used to find best SMC parameters while minimising objective functions during fault events. J1-J4 is the objective functions that may be defined as:

$$
\begin{aligned}
& J_{1}=\int_{0}^{t}\left(\left|\Delta V_{D C}\right|+\left|\Delta V_{P C C}\right|\right) d t \\
& J_{2}=\int_{0}^{t} t\left(\left|\Delta V_{D C}\right|+\left|\Delta V_{P C C}\right|\right) d t \\
& J_{3}=\int_{0}^{t}\left(\left(\Delta V_{D C}\right)^{2}+\left(\Delta V_{P C C}\right)^{2}\right) d t \\
& J_{4}=\int_{0}^{t} t\left(\left(V_{D C}\right)^{2}+\left(V_{P C C}\right)^{2}\right) d t
\end{aligned}
$$

Starting pollution is assumed for both controller parameters, and the goal function is computed using these initial values. Each particle's velocity and location are updated. As a result, the new objective function is established. Such a procedure is continued with continuous updates until either the near-optimal solution or the maximum no of iteration is reached. Finally, the population with highest chance of achieving the lowest goal function is calculated.

\section{Simulation RESUlts AND Discussions}

To demonstrate the efficacy of MOPSO sliding mode control, the system is simulated in SIMULINKTM/MATLAB using a SMC and a MOPSO controller. The SIMULINKTM/MATLAB is used for simulating the STATCOM and the hybrid off grid model. The MOGA and MOPSO are used to schedule the two sliding mode controller parameters for operating the STATCOM in a near-optimal manner. As a result, for the period of any abnormal operating situations, such as the Power Control Centre's unwanted three-phase faults, the entire system dynamic performance is improved. Fig. 5-7 show the Power Control Centre voltage with and without STATCOM. The Power Control Centre voltage profile was improved by adding the regulated STATCOM to the structure, with MOGA outperforming MOPSO. Because the Power Control Centre voltage changes inside the continuous operation zone, adding the proposed regulated STATCOM to the system at the Power Control Centre will keep the Renewable Energy Source operational during a three-phase failure. As a result, throughout this fault occurrence, the PV and wind systems will be operational. The DC voltage profile improves and falls within allowable levels when STATCOM is added to the system. During normal operation, no reactive power is exchanged between the system and the STATCOM. During this catastrophic failure, the STATCOM's job is to perform as a static volt-Ampere Reactive compensation, controlling the Power Control Centre voltage. In the face of wind gusts, STATCOMs are used to enhance the dynamic performance of hybrid systems based on non-linear renewable energy, such as PVs and WECS. It is a key concern to ensure the structure's efficient continued functioning of Renewable Energy Sources during failures. The reactive current supply between the STATCOM and hybrid system is managed by the relatively close programming of two SMCs utilizing the MOGA and MOPSO optimizers, respectively. According to numerical simulations, the MOPSO is an appropriate optimization for the relatively close gain scheduling of STATCOM SMC variables as an optimization approach. Using the MOPSO to operate the STATCOM instead of the MOGA allows the system's reactive power to be used during fault occurrences and wind gusts. As a consequence, correct STATCOM control effectively improves the dynamic functioning of the hybrid grid linked power structure, which comprises of PV and WECS systems. MOPSO outperforms MOGA in terms of dynamic performance in a blind qualitative and quantitative evaluation of the STATCOMSMC optimized by MOGA and MOPSO. 




(a)



(c)

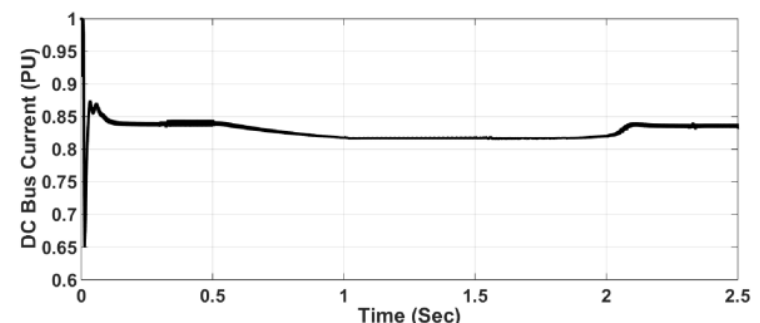

(b)



(d)

Fig.5. Transient response of DC voltage deviation, DC bus current, Id, Iq using MOPSO.



(a)

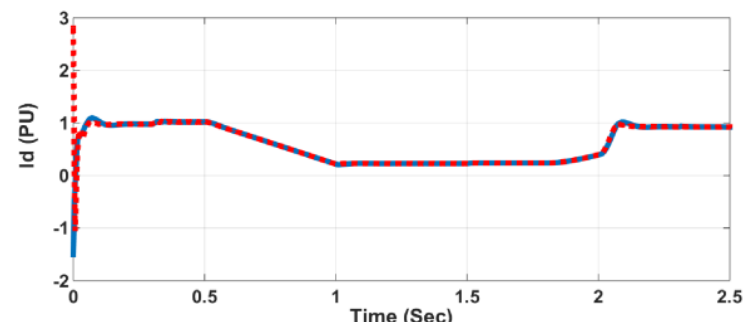

(c)



(b)

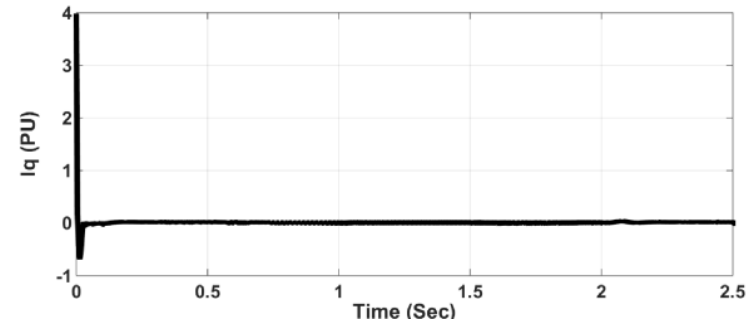

(d)

Fig.6 Transient response of DC voltage deviation, DC bus current, Id, Iq using MOGA

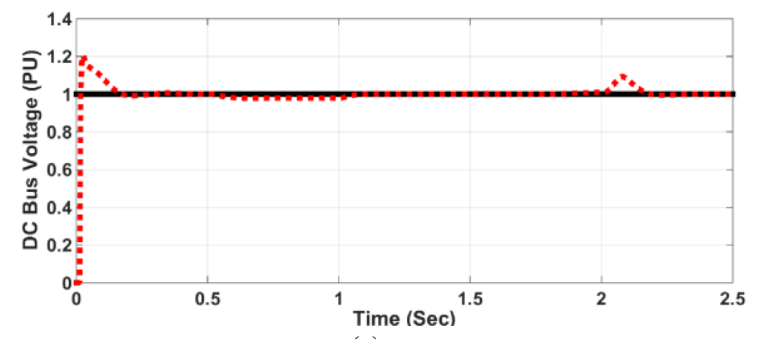

(a)



(c)

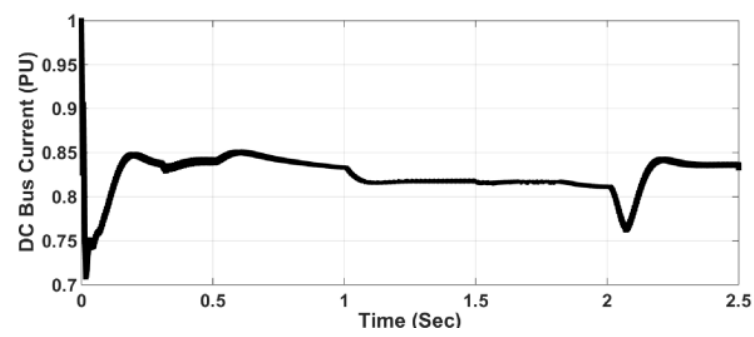

(b)

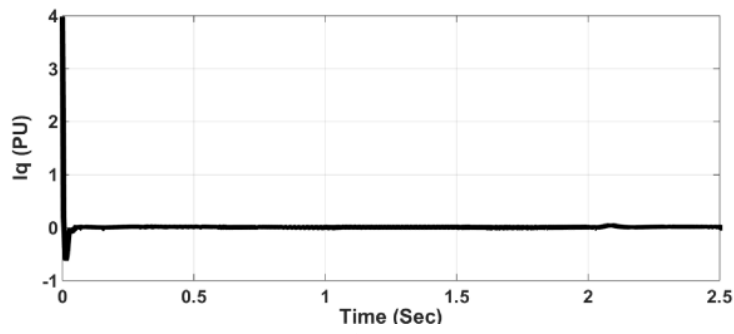

(d)

Fig.7 Transient response of DC voltage deviation, DC bus current, Id, Iq using Sliding Mode Controller.

\section{CONCLUSION}

To The innovative hybrid MOPSO-GA method is shown in this work to improve the settings of a SMC. The suggested approach is a hybrid of the MOPSO and GA algorithms. This method is based on utilizing the GA algorithm to initialize the MOPSO population, which has been shown to add considerably to convergence time while tackling various optimization problems. This paper's optimization of sliding mode controller settings also provides unique unbiased roles 
that tend to enhance the AVR system's step response quality. It is demonstrated that the optimum SMC with the optimal parameters outperforms the literature's equivalent controllers whose parameters are obtained by different techniques. By comparing the AVR system's step responses under nominal settings, performing a robustness study, and examining the AVR system's capacity to deal with various sorts of disturbances, the gains produced by using the MOPSO method in the optimization process are emphasized. Simulations of the passivity-based low-gain control method using a set of genuine DC-microgrid system characteristics have proven its efficacy and practical practicality. When there is parametric uncertainty in the DC-microgrid. The suggested controller's outcomes are compared to the outcomes of traditional PI inverter control to validate the simulation findings. It has been discovered that inverter control using MOPSO has a greater control effect and can enhance the structure's transient and steady state responsiveness. It showed improved voltage profile characteristics, decreased overshoot, and oscillation under varied operating conditions, as well as superior system performance in terms of rapid settling time during dynamic reactive power load conditions.

\section{REFERENCES}

[1] Miloud Rezkallah; Sanjeev Singh; Ambrish Chandra; Bhim Singh; Marco Tremblay; Maarouf Saad; Hua Geng "Comprehensive Controller Implementation for Wind-PV-Diesel Based Standalone Microgrid" IEEE Transactions on Industry Applications, Year: 2019 Volume: 55, Issue: 5.

[2] Ashu Verma; Ram Krishan; Sukumar Mishra "A Novel PV Inverter Control for Maximization of Wind Power Penetration" IEEE Transactions on Industry Applications, Year: 2018 | Volume: 54, Issue: 6.

[3] Ujjwal Kumar Kalla; Bhim Singh; S. Sreenivasa Murthy; Chinmay Jain; Krishan Kant "Adaptive Sliding Mode Control of Standalone Single-Phase Microgrid Using Hydro, Wind, and Solar PV ArrayBased Generation" IEEE Transactions on Smart Grid, Year: 2018 Volume: 9, Issue: 6.

[4] Farheen Chishti; Shadab Murshid; Bhim Singh "Robust Normalized Mixed-Norm Adaptive Control Scheme for PQ Improvement at PCC of a Remotely Located Wind-Solar PV-BES Microgrid" IEEE Transactions on Industrial Informatics, Year: 2020 | Volume: 16, Issue: 3.

[5] Bhim Singh; Rohini Sharma; Seema Kewat "Robust Control Strategies for SyRG-PV and Wind-Based Islanded Microgrid" IEEE Transactions on Industrial Electronics, Year: 2021 | Volume: 68, Issue: 4.

[6] Mohammad B. Shadmand; Robert S. Balog "Multi-Objective Optimization and Design of Photovoltaic-Wind Hybrid System for Community Smart DC Microgrid" IEEE Transactions on Smart Grid, Year: 2014 | Volume: 5, Issue: 5.

[7] R. C. Bansal, "Automatic Reactive-Power Control of Isolated WindDiesel Hybrid Power Systems", IEEE Transactions on Industrial Electronics, VOL. 53, NO. 4, August 2006.

[8] Jinning Liu, Li Zhang, Man Cao, "Power management and synchronization control of renewable energy microgrid based on STATCOM", IEEE Conference and Expo on Transportation Electrification Asia-Pacific (ITEC Asia-Pacific), 2014.

[9] D. Menniti, A. Pinnarelli, N. Sorrentino, "An hybrid PV-wind supply system with DStatcom interface for a water-lift station", International Symposium on Power Electronics Electrical Drives Automation and Motion (SPEEDAM), June 2010.

[10] G. Joos, B.T.Ooi, D. McGillis, F.D. Galiana and R. Marceau, " The Potential of Distributed Generation to Provide Ancillary Services", Power Engineering Society Summer Meeting, IEEE, July 2000.

[11] I. Sefa; N. Altin; S. Ozdemir; O. Kaplan, "Fuzzy PI controlled inverter for grid interactive renewable energy systems r," IET Renewable Power Generation, Volume: 9, Issue: 7, Pages: 729 - 738, 2015.

[12] Faramarz Karbakhsh, G. B. Gharehpetian, Jafar Milimonfared, Armin Teymoori,“" Three Phase Photovoltaic Grid-Tied Inverter Based on Feed-Forward Decoupling Control Using Fuzzy-PI Controller ,"7th Power Electronics, Drive Systems \&Technologies Conference , 16-18 Feb. 2016.
[13] Daugherity W C, Rathakrishnan B \& Yen J, "Performance evaluation of a self-tuning fuzzy controller," Proc. IEEE International Conference on Fuzzy Systems, 389-397, 8-12 March 1992.

[14] Hasanien HM. Design optimization of PID controller in automatic voltage regulator system using taguchi combined genetic algorithm method. IEEE Syst J 2013;7:825-31.

[15] Kim DH. Hybrid GA-BF based intelligent PID controller tuning for AVR system. Appl Soft Comput 2011;11:11-22.

[16] Ortiz-Quisbert ME, Duarte-Mermoud MA, Milla F, Castro-Linares R, Lefranc G. Optimal fractional order adaptive controllers for AVR applications. Electr Eng 2018;100:267-83.

[17] Pan I, Das S. Frequency domain design of fractional order PID controller for AVR system using chaotic multi-objective optimization. Int J Electr Power Energy Syst 2013;51:106-18.

[18] Pan I, Das S. Chaotic multi-objective optimization based design of fractional order PI kD 1 controller in AVR system. Int J Electr Power Energy Syst 2012;43:393-407.

[19] Gaing ZL. A particle swarm optimization approach for optimum design of PID controller in AVR system. IEEE Trans Energy Convers 2004;19:384-91

[20] Sahib MA, Ahmed BS. A new multiobjective performance criterion used in PID tuning optimization algorithms. J Adv Res 2016;7:125-34.

[21] Zamani M, Karimi-Ghartemani M, Sadati N, Parniani M. Design of a fractional order PID controller for an AVR using particle swarm optimization. Control Eng Pract 2009;17:1380-7.

[22] Ekinci S, Hekimoglu B. Improved kidney-inspired algorithm approach for tuning of PID controller in AVR system. IEEE Access 2019;7:39935-47.

[23] Mosaad AM, Attia MA, Abdelaziz AY. Whale optimization algorithm to tune PID and PIDA controllers on AVR system. Ain Shams Eng J 2019;10:755-67.

[24] Bingul Z, Karahan O. A novel performance criterion approach to optimum design of PID controller using cuckoo search algorithm for AVR system. J Franklin Inst 2018;355:5534-59.

[25] Sikander A, Thakur P, Bansal RC, Rajasekar S. A novel technique to design cuckoo search based FOPID controller for AVR in power systems. Comput Electr Eng 2018;70:261-74.

[26] Blondin MJ, Sicard P, Pardalos PM. Controller Tuning Approach with robustness, stability and dynamic criteria for the original AVR System. Math Comput Simul 2019;163:168-82.

[27] Blondin MJ, Sanchis J, Sicard P, Herrero JM. New optimal controller tuning method for an AVR system using a simplified Ant Colony Optimization with a new constrained Nelder-Mead algorithm. Appl Soft Comput 2018;62:216-29.

[28] Chatterjee S, Mukherjee V. PID controller for automatic voltage regulator using teaching-learning based optimization technique. Int J Electr Power Energy Syst 2016;77:418-29.

[29] Panda S, Sahu BK, Mohanty PK. Design and performance analysis of PID controller for an automatic voltage regulator system using simplified particle swarm optimization. J Franklin Inst 2012;349:260925.

[30] Dos Santos Coelho L. Tuning of PID controller for an automatic regulator voltage system using chaotic optimization approach. Chaos, Solitons Fractals 2009;39:1504-14

[31] Çelik E, Durgut R. Performance enhancement of automatic voltage regulator by modified cost function and symbiotic organisms search algorithm. Eng Sci Technol Int J 2018;21:1104-11.

[32] Gozde H, Taplamacioglu MC. Comparative performance analysis of artificial bee colony algorithm for automatic voltage regulator (AVR) system. J Franklin Inst 2011;348:1927-46.

[33] Zhang D-L, Tang Y-G, Guan X-P. Optimum design of fractional order PID controller for an AVR system using an improved artificial bee colony algorithm. Acta Autom Sin 2014;40:973-9.

[34] Mosaad AM, Attia MA, Abdelaziz AY. Comparative performance analysis of AVR controllers using modern optimization techniques. Electr Power Compon Syst 2018;46:2117-30

[35] Chatterjee A, Mukherjee V, Ghoshal SP. Velocity relaxed and craziness-based swarm optimized intelligent PID and PSS controlled AVR system. Int J Electr Power Energy Syst 2009;31:323-33.

[36] Tang Y, Cui M, Hua C, Li L, Yang Y. Optimum design of fractional order PI kD 1 controller for AVR system using chaotic ant swarm. Expert Syst Appl 2012;39:6887-96.

[37] Zhu H, Li L, Zhao Y, Guo Y, Yang Y. CAS algorithm-based optimum design of PID controller in AVR system. Chaos, Solitons Fractals 2009;42:792-800

[38] Zeng GQ, Chen J, Dai YX, Li LM, Zheng CW, Chen MR. Design of fractional order PID controller for automatic regulator voltage system based on multi-objective extremal optimization. Neurocomputing 2015;160:173-84 